\section{Retrospective comparison of negative pressure wound therapy and silver-coated foam dressings in open-wound treatment in cats}

Journal of Feline Medicine and Surgery 2017, Vol. 19(6) 624-630 (C) The Author(s) 2016 Reprints and permissions: sagepub.co.uk/journalsPermissions.nav DOI: $10.1177 / 1098612 \times 16645141$ journals.sagepub.com/home/jfms

This paper was handled and processed by the European Editorial Office (ISFM) for publication in JFMS

\title{
(SAGE
}

\author{
Mirja Christine Nolff' ${ }^{1}$, Michael Fehr ${ }^{2}$, Sven Reese ${ }^{3}$ \\ and Andrea E Meyer-Lindenberg ${ }^{1}$
}

\begin{abstract}
Objectives The objective of this study was to evaluate negative pressure wound therapy (NPWT) for the treatment of complicated wounds in cats.

Methods Twenty cats undergoing open-wound treatment in two clinics were classed according to treatment method: NPWT (group $A, n=10$ ) and polyurethane foam dressing (group $B, n=10$ ). Pairs of patients from each group were matched based on wound conformation, localisation and underlying cause. Cats from both groups were compared in terms of duration of previous treatment, time to closure and complications.

Results Signalment, duration of previous treatment, antibiotic and antiseptic treatment, and bacterial status were comparable between groups. Total time to wound closure was significantly shorter $(P=0.046$, strong effect size; Cohen $\mathrm{d}=0.8$ ) in group A (25.8 days, range 11.0-57.0 days) compared with group B (39.5 days, range 28.0-75.0 days). NPWT-treated wounds suffered fewer complications and became septic less frequently during treatment compared with wounds treated with a foam dressing. The progression of fat tissue necrosis was particularly well controlled under NPWT, resulting in fewer deaths due to this condition in this group. However, although a strong effect of NPWT on the progression of infection, fever and sepsis was detected (Cramer-V 0.5), this difference was not significant.

Conclusions and relevance This study demonstrated that time to healing was considerably shorter, and complication rate lower, in NPWT-treated animals compared with foam dressing-treated cats. In particular, the effective management of infection by NPWT emphasises the value of NPWT in the treatment of cats suffering from infected wounds.
\end{abstract}

Accepted: 25 March 2016

\section{Introduction}

Negative pressure wound therapy (NPWT) involves the improvement of wound healing by the application of a homogeneous vacuum to the wound via a sponge. ${ }^{1}$ Although the main effects by which NPWT improves wound healing have been elucidated, the full extent of NPWT is yet to be discovered..$^{2-10}$ Over the past 10 years indications such as urine-induced necrosis, burn injuries, augmentation of shear injuries, augmentation of local flaps and septic peritonitis have been described in the veterinary literature. ${ }^{11-22}$ Experimental and retrospective clinical trials in dogs have demonstrated the positive effect of NPWT for wound treatment in dogs; $21-24$ however, data from canine patients may not reflect the situation in cats, as considerable differences regarding wound-healing capacities exist between these species. ${ }^{25-27}$ Cats have a poorer healing response than dogs,

${ }^{1}$ Clinic for Small Animal Surgery and Reproduction, Ludwig-

Maximilians University, Munich, Germany

${ }^{2}$ Foundation, Small Animal Clinic, University of Veterinary

Medicine Hannover, Hannover, Germany

${ }^{3}$ Department for Basic Veterinary Sciences, Ludwig-Maximilians

University, Munich, Germany

\section{Corresponding author:}

Mirja Christine Nolff Dr Med Vet, Clinic for Small Animal Surgery and Reproduction, Ludwig-Maximilians-University, Veterinärstrasse 13, 80539 Munich, Germany

Email: m.nolff@Imu.de 
with less effective granulation. ${ }^{26,27}$ Thus, NPWT would seem to be an especially promising tool in this species, especially for encouraging granulation. Unfortunately, despite the publication of several case reports and case studies, there is, as yet, no controlled clinical study evaluating the value of this technique in cats. The aim of this study was to evaluate the outcome of NPWT when used for open-wound therapy in cats, and to compare it to a standard treatment protocol.

\section{Materials and methods}

The medical records of two clinics in the period between January 2011 and October 2015 were searched for cats that underwent open-wound therapy. Records were included if dressing changes, time to closure and a minimum follow-up of 14 days after closure were documented. Based on the type of treatment, cats were assigned to two groups: group A (NPWT) and group B (polyurethane foam dressing). Matched pairs were created by assigning each cat in group A a corresponding partner from group B. After matching, a total of 10 cat pairs (20 cats) were included for further statistical evaluation (see table in the supplementary material).

\section{Treatment protocols}

Group A cats were treated by application of a NPWT dressing after initial debridement (VAC GranuFoam, TracPad and VAC Freedom; all KCI) (Figure 1). Dressing changes were performed every 2 or 3 days with the cat was under general anaesthesia. A continuous vacuum of $-125 \mathrm{mmHg}$ was applied to the wound. NPWT was discontinued once a healthy granulation bed had formed and wound exudation had decreased. Thereafter, wounds were closed, if possible. In cases were a delayed closure was not possible, therapy was continued using a triple layered silver-coated foam dressing (Acticoat Moisture Control; Smith\&Nephew) until the wound was healed.

In group B, wound treatment was identical to group A except that a perforated honeycomb film-coated highly absorbent foam (Alleyvin Cavity; Smith\&Nephew) was initially applied as long as heavy wound exudation occurred. After exudation levels decreased, the dressing was changed to a silver-coated foam dressing (Acticoat Moisture Control; Figure 1). Foam dressings were directly sutured to the wounds to prevent dislodging, and dressing changes were performed every 2-3 days, while the cat was under general anaesthesia. Surgical advancement of the wound edges was performed during dressing changes in all cats of both groups when possible: the wound edges were undermined by approximately $1-2 \mathrm{~cm}$, and the skin was advanced toward the centre of the defect and secured there using walking sutures. In this way, the wound size could be reduced while keeping the wound open and allowing maximal wound drainage, as most of the cats were severely infected and had already failed previous attempts at closure.

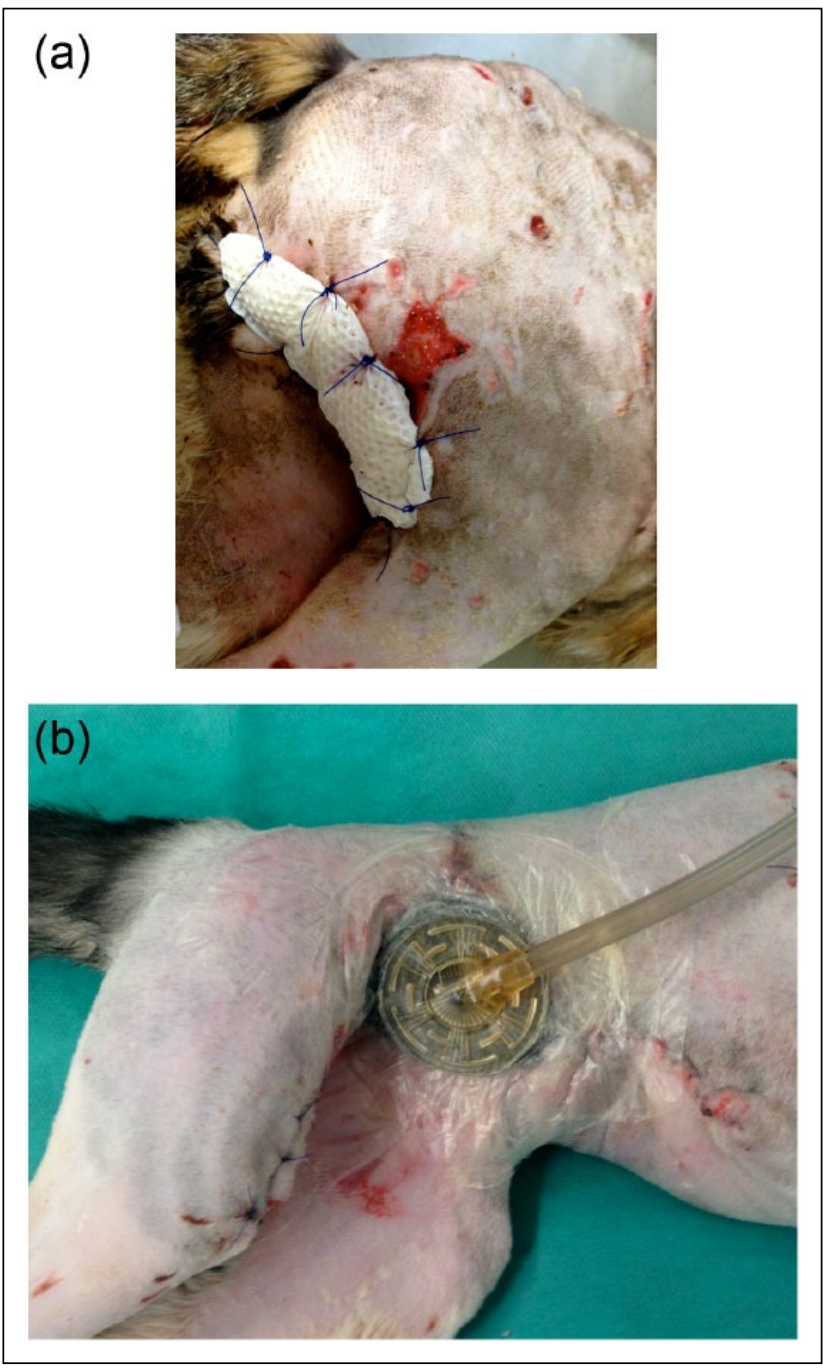

Figure 1 Demonstrating the two different wound dressings in place: (a) foam, (b) negative pressure wound therapy

\section{Study design}

For each cat, signalment data, including breed, age, sex and weight, were recorded, as well as known comorbidities. In addition, initial antibiotic treatment and the antibiotic drug used, as well as changes in the antibiotic therapy due to the results of resistance testing and antiseptic treatment, were recorded.

Wounds were further characterised using the following parameters: duration of previous treatment, cause of wound development, wound type (acute or chronic), location of the wound, presence of infection (swelling, pain, discharge, presence of necrosis) and wound class $(1=$ small defect, no wound pockets; $2=$ medium-sized defect, no wound pockets; 3 = medium-sized defect with pockets or large defect without pockets; $4=$ large defect) at the initiation of the documented treatment.

If available, the microbial status of the wound at initiation of therapy and during treatment, including the number of isolated bacterial species and their resistance profiles, was recorded and compared between groups. 
To record outcome, we noted the following information: closure rate, total time to closure and complications observed during therapy and after closure.

\section{Statistical analysis}

Statistical analysis was performed using SPSS 20.0 (IBM). Categorical variables were expressed as frequencies, and continuous data were expressed as median and range. A paired $t$-test was used to assess differences between groups for continuous, normally distributed data, and a Wilcoxon rank sum test was used for non-normally distributed parameters. A Fisher's exact test was used to compare categorical variables. The effect sizes were calculated using Cohen $\mathrm{d}$ for continuous data and Cramér's V test for categorical data. Significance was set at $P<0.05$.

\section{Results}

\section{Signalment}

The mean age of cats in group A was 5.8 years (range 2.011.0 years), and their mean body weight was $4.7 \mathrm{~kg}$ (range $3.3-5.8 \mathrm{~kg}$ ). The corresponding partners in group B had a mean age of 5.3 years (range 3.0-14.0 years), and a mean body weight of $4.4 \mathrm{~kg}$ (range $3.3-7.3 \mathrm{~kg}$ ). Further details are listed in the table in the supplementary material.

\section{Previous treatment and comorbidities}

Six cats in group A and seven in group B received previous wound treatment before presentation. Of these, five (group A) and seven (group B) cats had undergone previous surgical treatment (Table 1). The mean treatment duration was 7 days in group A (range 5-8 days) and 10 days in group B (range 6-22 days). Details regarding comorbidities are given in the table in the supplementary material. No statistical differences between the groups were detectable for any of these parameters.

\section{Antibiotic medication}

The main antibiotic used for treatment was amoxicillin/ clavulanic acid. Additional antibiotics used for initial treatment included marbofloxacin, metronidazole, doxycycline, cefazolin, ceftiofur and gentamicin. There was no

Table 1 Characterisation of previous treatment of patients before inclusion in the study

\begin{tabular}{|c|c|c|}
\hline & $\begin{array}{l}\text { Group A } \\
(n=10)\end{array}$ & $\begin{array}{l}\text { Group B } \\
(n=10)\end{array}$ \\
\hline Previous treatment & 6 & 7 \\
\hline Antibiotic treatment & 6 & 7 \\
\hline Surgical debridement with drains & 5 & 7 \\
\hline Open-wound treatment & 1 & 0 \\
\hline $\begin{array}{l}\text { Duration of previous treatment } \\
\text { (days) }\end{array}$ & $\begin{array}{l}7 \\
\text { (range } \\
5-8)\end{array}$ & $\begin{array}{l}10 \\
\text { (range } \\
6-22 \text { ) }\end{array}$ \\
\hline
\end{tabular}

Data are number of cats unless otherwise indicated significant difference between treatment regimen or antibiotic between groups. Further details are given in Table 2 .

\section{Antiseptic treatment}

Polyhexanide $0.04 \%$ was used in all cases. In three cats in group A, this was changed to $1 \%$ acetic acid as bacterial culturing had found multidrug resistant Pseudomonas aeruginosa to be present (Table 2).

\section{Bacterial culture}

Bacterial culture results at initial debridement were available for 10 cats in group A and eight in group B. In both groups, the median number of bacterial species isolated at initial debridement was 2 (range $0-7$ group A; range $1-5$ group $B$ ). One cat in group A and none in group B were initially tested bacteriologically negative. Isolated bacteria species included Escherichia coli $(\mathrm{n}=5$, group A; $\mathrm{n}=5$, group $\mathrm{B})$, Enterococcus species $(\mathrm{n}=3$, group $\mathrm{A}$; $\mathrm{n}=5$, group $\mathrm{B})$, Enterobacter species $(\mathrm{n}=1$, group $\mathrm{A}$; $\mathrm{n}=2$, group B), Staphylococcus pseudintermedius $(\mathrm{n}=2$, group B), Staphylococcus aureus ( $n=3$, group $A ; n=1$, group B), Staphylococcus species $(\mathrm{n}=2$, group $\mathrm{A} ; \mathrm{n}=1$, group $\mathrm{B})$, $P$ aeruginosa $(\mathrm{n}=1$, group $\mathrm{A})$, Bacteroides species $(\mathrm{n}=1$, group $B)$, Pasteurella multocida $(n=3$, group $A ; n=1$, group B), Corynebacterium species $(\mathrm{n}=1$, group $\mathrm{B})$, Prevotella species $(n=1$, group B), Pantoea species $(n=1$, group $A)$, Clostridium species ( $\mathrm{n}=1$, group $\mathrm{A})$ and Citrobacter species ( $n=1$, group A). In 4/9 cats in group $A$ and $6 / 8$ cats in group $\mathrm{B}$ the identified isolates were resistant to more than three antibiotic classes.

Repeated bacterial culture results during therapy were available for 10 cats in group A and four cats in group B. The mean number of isolated bacterial species during therapy was 1 in both groups (range $0-3$ ). Isolated species included Enterococcus species $(\mathrm{n}=3), E$ coli $(\mathrm{n}=$ $4)$, Enterobacter species $(\mathrm{n}=1), S$ aureus $(\mathrm{n}=2)$, $P$ aeruginosa $(\mathrm{n}=2)$. No statistical differences were detected between groups.

Two of nine cats in group A that had positive bacterial culture results at the beginning became negative over the course of the treatment. In group B, three patients with follow-up cultures tested negative. In the fourth cat in which a follow-up culture was available, multidrug resistant isolates of $E$ coli and Enterococcus species were identified (this cat died).

\section{Wound characteristics}

The majority of wounds were major (class 3-4), all wounds were considered acute and the most frequent underlying cause of open-wound treatment was infection (surgical site infection, fat tissue necrosis, necrotising fasciitis or other soft tissue infections precluding successful primary closure), followed by trauma (Table 3 ). Localisation of wounds was as follows: limb (group A, 5/10; group B, 4/10), hip (group B, 1/10), abdomen 
Table 2 Antibiotic and antiseptic treatment of the patients expressed as number of patients treated

\begin{tabular}{|c|c|c|}
\hline & $\begin{array}{l}\text { Group A } \\
(n=10)\end{array}$ & $\begin{array}{l}\text { Group B } \\
(n=10)\end{array}$ \\
\hline Bacterial culture available & 10 & 8 \\
\hline Antibiotic treatment during therapy & 9 & 9 \\
\hline Monotherapy & 4 & 7 \\
\hline Amoxicillin/clavulanic acid & 3 & 3 \\
\hline Cefazolin & 1 & 0 \\
\hline Ceftiofur & 0 & 1 \\
\hline Doxycycline & 0 & 3 \\
\hline Multiple antibiotics & 5 & 2 \\
\hline $\begin{array}{l}\text { Amoxicillin/clavulanic acid }+ \\
\text { metronidazole }\end{array}$ & 3 & 1 \\
\hline $\begin{array}{l}\text { Amoxicillin/clavulanic acid }+ \\
\text { metronidazole }+ \text { ceftiofur }\end{array}$ & 0 & 1 \\
\hline $\begin{array}{l}\text { Amoxicillin/clavulanic acid }+ \\
\text { metronidazole }+ \text { marbofloxacin }\end{array}$ & 1 & 0 \\
\hline $\begin{array}{l}\text { Amoxicillin/clavulanic acid }+ \\
\text { metronidazole }+ \text { gentamicin }\end{array}$ & 1 & 0 \\
\hline Based on susceptibility testing & 9 & 8 \\
\hline Adjusted during treatment & 6 & 4 \\
\hline Marbofloxacin & 5 & 2 \\
\hline Doxycycline & 1 & 2 \\
\hline Discontinued during treatment & 2 & 0 \\
\hline Antiseptic treatment during therapy & 10 & 10 \\
\hline Polyhexanide & 10 & 10 \\
\hline Acetic acid & 3 & 0 \\
\hline
\end{tabular}

(group A, 1/10; group B, 1/10), mammary glands (group A, 3/10; group B, 3/10) and vast defects, including the lateral and ventral abdominal wall and thigh after amputation (1/10 in both group A and group B).

All wounds in group $A$ and 9/10 wounds in group B appeared clinically infected at the beginning of openwound treatment.

\section{Outcome}

Closure was achieved in nine cats in group A and six in group B. None of the cats with wound closure in group A developed further complications after closure (follow-up at the time of writing between 1 and 4 years), while three of the wounds that had been closed in group B had to be revised owing to partial breakdown or recurring infection.

One cat in group A was euthanased before closure. In this case, the underlying reason for open treatment was necrotising fasciitis. Although the cat recovered well initially, it developed severe anaemia after infection and the owners declined treatment with fresh blood. The cat was therefore euthanased 14 days after initial surgery. In one cat from group B, treatment had to be discontinued and was changed to NPWT, owing to progressing infection and delay of granulation. Subsequent wound healing was uneventful. The remaining three cats in group B, where closure was not achieved, all displayed signs of ongoing local inflammation and sepsis (in one case

Table 3 Wound characteristics for patients in the study

\begin{tabular}{|c|c|c|c|}
\hline & Group A $(n=10)$ & Group B $(n=10)$ & $P^{*}$ \\
\hline Clinically infected & 10 & 9 & \\
\hline Acute & 10 & 10 & \\
\hline Chronic & 0 & 0 & \\
\hline Class 1 & 0 & 1 & \\
\hline Class 2 & 2 & 3 & \\
\hline Class 3 & 8 & 6 & \\
\hline \multicolumn{4}{|l|}{ Cause } \\
\hline Trauma & 4 & 5 & \\
\hline Infection total & 6 & 5 & \\
\hline Necrotising fasciitis & $2^{\dagger}$ & 0 & \\
\hline Fat tissue necrosis & $3^{\dagger}$ & $3^{+}$ & \\
\hline Surgical site infection & $1^{\dagger}$ & $2^{+}$ & \\
\hline Closure achieved & 9 & 6 & \\
\hline Time to closure (days) & 25.8 (range $11.0-57.0$ ) & 39.5 (range 28.0-75.0 days) & 0.046 \\
\hline Number of bandage changes & 5.4 & 7.8 & 0.041 \\
\hline Complications during therapy & 3 & 5 & \\
\hline Ongoing sepsis & 1 & 3 & \\
\hline Ongoing infection & 3 & 5 & \\
\hline Ongoing fat tissue necrosis & 0 & 3 & \\
\hline Death & 1 & 3 & \\
\hline Complications after closure & 0 & 3 & \\
\hline Revisions after closure & 0 & 3 & \\
\hline
\end{tabular}

Data are number of cats unless otherwise indicated

*Only given for significant differences

tIndividual number of patients with different types of infection 
ongoing fat tissue necrosis). Two of these cats died and the third was euthanased.

The complication rate during therapy $(5 / 10$ in group B vs $2 / 10$ in group A) and after closure ( $3 / 6$ in group $B$ vs $0 / 9$ in group A) was higher in group B. However, although a strong effect of treatment was detectable with regard to wound-associated mortality, ongoing sepsis, ongoing wound infection, ongoing fat tissue necrosis and fever (Cramer-V 0.5), these differences were not statistically significant $(P>0.05$; Figure 2$)$.

\section{Total time to closure}

Total time to closure was significantly shorter $(P=0.046)$ in cats from group A (25.8 days, range 11.0-57.0 days) when compared with corresponding cats from group B (39.5 days, range 28.0-75.0 days). The effect of therapy on time to closure was strong (Cohen d 0.8).

\section{Discussion}

Numerous publications have reported the beneficial effect of NPWT on the healing of complicated wounds in humans and animals, ${ }^{1-20}$ but information regarding cats was limited to a number of case reports and a case study. ${ }^{17,19,28-30}$ Here, we demonstrated faster wound closure in cats undergoing NPWT compared with foamtreated animals.

Wounds can be very heterogeneous: the age of the cat, as well as the size, age and location of the wound, and the presence of infection strongly influence wound healing. ${ }^{31}$ Comparison of the groups without regard to these parameters would have biased our evaluation. In order to compensate for this, matched pairs of cats were assigned for evaluation of outcome parameters (see supplementary material).

There are numerous wound dressings available. Wetto-dry and dry-to-dry bandages have been frequently used in open-wound treatment, but these bandages lead to mechanical debridement of the wound surface during dressing changes, even if a non-adherent gauze is interposed. ${ }^{31}$ Moreover, the wound exudate is absorbed or evaporates through the dressing, leading to the loss of growth factors and cells during therapy. ${ }^{31}$ Such dressings are therefore no longer considered to meet the standard of care required in human medicine, and their use in veterinary patients should be limited as more effective options are available..$^{32}$ Moist wound healing has overcome these limitations, and supports the needs of the wound with regard to temperature, moisture, osmolarity and gas exchange. ${ }^{32,33}$ Unfortunately, information regarding the effect of such treatment in small animals is rare, and so far no studies exist evaluating their effect in cats. This is especially problematic, as cats show poorer wound healing capacities than dogs, which can lead to impaired healing. ${ }^{25-27}$ In addition, shear injuries from car accidents are especially frequent. ${ }^{34}$ Besides other indications, effective and fast establishment of granulation is critical for further treatment in these cases. ${ }^{34}$ Improving wound-healing protocols for cats is thus of paramount importance.

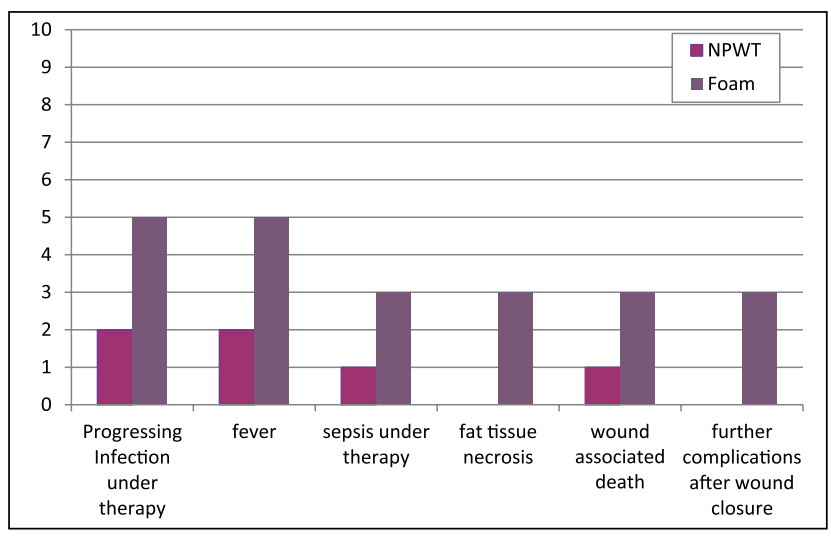

Figure 2 Graph showing the differences in occurrence of complications per group (given in number of cats). NPWT = negative pressure wound therapy

In the past, the standard dressing for moist wound healing in both institutions taking part in this study was soft perforated film-coated polyurethane foam dressing for highly exudative wounds, and a triple-layered silver-coated foam dressing in wounds when exudation was at, or decreased to, normal levels. The use of silver-coated foam prevents maceration of the periwound skin area, reduced clinical signs of infection and wound area, and promoted healing. ${ }^{35}$ Silver ions have been shown to have antimicrobial efficacy against bacteria that are resistant to various antibiotics in vitro, and various silver dressings have been shown to reduce bacterial load in infected wounds in vivo. ${ }^{18,36-38}$ However, these findings are still under debate, and results from open-wound therapy in dogs do not support this. ${ }^{23}$

Wackenfors et al stated that the physiological and molecular biological mechanisms by which VAC therapy (NPWT) accelerates wound healing are to a large extend unknown'. ${ }^{9}$ However, the following effects of NPWT have been proposed to be responsible for its efficacy: a uniform reduction of interstitial oedema due to active fluid drainage leading to a reduction of interstitial pressure and an increase of blood flow within the tissue under the sponge. $3,8,9$ This increase of up to $50 \%$ in perfusion levels can be achieved up to $1.5 \mathrm{~cm}$ under the sponge, and the effect of the vacuum extends as far as $3 \mathrm{~cm}$ under the sponge. ${ }^{8}$ Studies of the effect of vacuum on tissue perfusion found that a negative pressure of $-125 \mathrm{mmHg}$ was most effective at promoting perfusion, while higher values impaired blood flow. ${ }^{3}$ A significant increase in the amount of granulation tissue formation when compared with control groups using standard open-wound management, $, 321,39,40$ a fact that might be of particular importance in cats. This effect is thought to be due to the enhancement of fibroblast proliferation due to mechanical cell deformation..$^{10,40}$ Fast and smooth granulation of wounds under NPWT has been shown experimentally and in a retrospective clinical study in dogs..$^{21,23}$ 
Our results clearly demonstrate two effects of NPWT: significantly faster wound closure and effective infection control.

In the NPWT group the initial condition of the cats was slightly worse than in the foam group, in terms of the number of septic, anaemic and febrile cats at initiation of therapy. Moreover, two special cases - cats with necrotising fasciitis - were included in this group. This is a condition with very high morbidity; in fact, most reported feline necrotising fasciitis cases were postmortem diagnoses, with only two reported survivors of this condition so far. Given this fact, the closure rate of the two cats with necrotising fasciitis in this study are particularly noteworthy. With the exception of the cat affected by necrotising fasciitis that has already been presented in septic shock but nonetheless survived for 14 days, all cats in the NPWT group survived and achieved closure. By contrast, in spite of less severe conditions than necrotising fasciitis, four cats did not achieve closure in the foam group. In one cat, severe progression of the infection led to euthanasia, and two others died. In the fourth cat, ongoing postoperative infection with multidrug resistant bacteria necessitated open-wound treatment; however, 10 days of open management with foam failed to control the infection. Treatment was changed to NPWT at day 10, whereupon the wound began granulation and finally closed. This case elegantly demonstrates that infection and local tissue damage can be more effectively managed under NPWT than under standard treatment. In fat tissue necrosis, exudate management often becomes an issue. This is easily controlled using NPWT. Progression of fat tissue necrosis after initiation of NPWT was not observed in any cat in this study. The difference in complication rate, survival and closure warrants further investigation, and strongly supports the use of NPWT in cats. In addition, of the six cats in which closure was achieved using foam treatment, three had to be revised after closure, owing to dehiscence or recurrent infection. This was not necessary in any of the cats receiving NPWT. The effect of NPWT on infection that we documented is most likely due to the increase in perfusion under NPWT. Increased perfusion bolsters the immune response. This, combined with the improved removal of fluid from the wound, and thus improved clearance of bacterial virulence factors within these secretions, results in effective control of infection. ${ }^{3,5,6}$ However, we were not able to determine a significant effect of therapy on the parameters of wound-related death, fever and ongoing sepsis. Further prospective studies should be performed to measure objectively the effect of NPWT on exudation, granulation, perfusion, local immune response and wound size development.

Another postulated benefit of NPWT is enhanced bacterial clearance. ${ }^{3,41-43}$ In general, wound bioburden in cats becomes comparable with that of dogs under open treatment, and these bacteria are frequently multidrug resistant. The bacteria isolated in this study during therapy support this observation. As in dogs, we were not able to detect differences regarding bacterial clearance under NPWT or foam treatment; however, managing the damage caused by bacteria may be more important than achieving bacterial clearance. The number of available follow-up cultures in the foam group was very limited, so this finding would benefit from future re-evaluation.

\section{Conclusions}

NPWT leads to more rapid wound healing in cats, and, in particular, reduces the complication rate, especially due to infection, when compared with foam dressings. Although the number of cats included in the study was small, a major effect was detected, indicating the value of this therapy in cats. Further studies are needed to verify these promising results.

Supplementary material Overview of signalment (gender, breed, age, body weight), wound details (classification of wound extent, wound age, underlying cause, infection status, localisation) comorbidities and time to closure in matched patients.

Conflict of interest The authors declared no potential conflicts of interest with respect to the research, authorship, and/ or publication of this article.

Funding The authors received no financial support for the research, authorship, and/or publication of this article.

\section{References}

1 Rozhdestvin VA, Nurgaliev TN and Kiverov SV. Vacuumaspiration in the treatment of stab wounds of soft tissues. Ortop Traumatol Protez 1987; 32: 32-36.

2 Voinchet V and Magalon G. Vacuum assisted closure. Wound healing by negative pressure. Ann Chir Plast Esthet 1996; c41: 583-589.

3 Morykwas MJ, Argenta LC, Shelton-Brown EI, et al. Vacuum-assisted closure: a new method for wound control and treatment: animal studies and basic foundation. Ann Plast Surg 1997; 38: 553-562.

4 Isago T, Nozaki M, Kikuchi Y, et al. Effects of different negative pressures on reduction of wounds in negative pressure dressings. J Dermatol 2003; 30: 596-601.

5 Jones SM, Banwell PE and Shakespeare PG. Advances in wound healing: topical negative pressure therapy. Postgrad Med J 2005; 81: 353-357.

6 Argenta LC, Morykwas MJ, Marks MW, et al. Vacuumassisted closure: state of clinic art. Plast Reconstr Surg 2006; 117: 127S-142S.

7 Banwell $\mathrm{P}$ and Teot L. Topical negative pressure (TNP): the evolution of a novel wound therapy. J Tissue Viability 2006; 16: 16-24.

8 Wackenfors A, Gustafsson R, Sjogren J, et al. Blood flow responses in the peristernal thoracic wall during vacuum-assisted closure therapy. Ann Thorac Surg 2005; 79: 1724-1730. 
9 Wackenfors A, Sjogren J, Gustafsson R, et al. Effects of vacuum-assisted closure therapy on inguinal wound edge microvascular blood flow. Wound Repair Regen 2004; 12: 600-606.

10 McNulty AK, Schmidt M, Feeley T, et al. Effects of negative pressure wound therapy on fibroblast viability, chemotactic signaling, and proliferation in a provisional wound (fibrin) matrix. Wound Repair Regen 2007; 15: 838-846.

11 Bertran J, Farrell M and Fitzpatrick N. Successful wound healing over exposed metal implants using vacuumassisted wound closure in a dog. J Small Anim Pract 2013; 54: 381-385.

12 Bristow PC, Perry KL, Halfacree ZJ, et al. Use of vacuumassisted closure to maintain viability of a skin flap in a dog. J Am Vet Med Assoc 2013; 243: 863-868.

13 Buote NJ and Havig ME. The use of vacuum-assisted closure in the management of septic peritonitis in six dogs. J Am Anim Hosp Assoc 2012; 48: 164-171.

14 Cioffi KM, Schmiedt CW, Cornell KK, et al. Retrospective evaluation of vacuum assisted peritoneal drainage for the treatment of septic peritonitis in dogs and cats: 8 cases (2003-2010). J Vet Emerg Crit Care 2012; 22: 601-609.

15 Kirkby KA, Wheeler J, Farese J, et al. Surgical views: vacuum-assisted wound closure: clinical applications. Compend Contin Educ Vet 2010; 32: E1-E6.

16 Kirkby KA, Wheeler J, Farese J, et al. Surgical views. Vacuum-assisted wound closure: application and mechanism of action. Compend Contin Educ Vet 2009; 31: E1-E5.

17 Owen L, Hotston-Moore A and Holt P. Vacuum-assisted wound closure following urine-induced skin and thigh muscle necrosis in a cat. Vet Comp Orthop Traumatol 2009; 22: 417-421.

18 Mullally C, Carey K and Seshadri R. Use of a nanocrystalline silver dressing and vacuum-assisted closure in a severely burned dog. J Vet Emerg Crit Care 2010; 20: 456-463.

19 Guille AE, Tseng LW and Orsher RJ. Use of vacuumassisted closure for management of a large skin wound in a cat. $J$ Am Vet Med Assoc 2007; 230: 1669-1673.

20 Ben-Amotz R, Lanz OI, Miller JM, et al. The use of vacuum assisted closure therapy for the treatment of distal extremity wounds in 15 dogs. Vet Surg 2007; 36: 684-690.

21 Demaria M, Stanley BJ, Hauptman JG, et al. Effects of negative pressure wound therapy on healing of open wounds in dogs. Vet Surg 2011; 40: 658-669.

22 Stanley BJ, Pitt KA, Weder CD, et al. Effects of negative pressure wound therapy on healing of free full-thickness skin grafts in dogs. Vet Surg 2013; 42: 511-522.

23 Nolff MC, Fehr M, Bolling A, et al. Negative pressure wound therapy, silver coated foam dressing and conventional bandages in open wound treatment in dogs. A retrospective comparison of $\mathbf{5 0}$ paired cases. Vet Comp Orthop Traumatol 2015; 28: 30-38.

24 Pitt KA and Stanley BJ. Negative pressure wound therapy: experience in 45 dogs. Vet Surg 2014; 43: 380-387.

25 Bohling MW and Henderson RA. Differences in cutaneous wound healing between dogs and cats. Vet Clin North Am Small Anim Pract 2006; 36: 687-692.

26 Bohling MW, Henderson RA, Swaim SF, et al. Comparison of the role of the subcutaneous tissues in cutaneous wound healing in the dog and cat. Vet Surg 2006; 35: 3-14.
27 Bohling MW, Henderson RA, Swaim SF, et al. Cutaneous wound healing in the cat: a macroscopic description and comparison with cutaneous wound healing in the dog. Vet Surg 2004; 33: 579-587.

28 Woods S, De Castro Marques AL, Renwick MG, et al. Nanocrystalline silver dressing and subatmospheric pressure therapy following neoadjuvant radiation therapy and surgical excision of a feline injection site sarcoma. J Feline Med Surg 2012; 14: 214-218.

29 Nolff MC and Meyer-Lindenberg A. Necrotising fasciitis in a domestic shorthair cat-negative pressure wound therapy assisted debridement and reconstruction. J Small Anim Pract 2015; 56: 281-284

30 Nolff MC and Meyer-Lindenberg A. Negative pressure wound therapy augmented full-thickness free skin grafting in the cat: outcome in $\mathbf{1 0}$ grafts transferred to six cats. J Feline Med Surg 2015; 17: 1041-1048

31 Amalsadvala T and Swaim SF. Management of hard to heal wounds. Vet Clin Small Anim 2006; 36; 693-711.

32 Campbell BG. Dressings, bandages, and splints for wound management in dogs and cats. Vet Clin Small Anim 2006; 36: 759-791.

33 Bolton LL, Monte K and Pirone LA. Moisture and healing:beyond the jargon. Ostomy Wound Manage 2000; 46 Suppl 1A: 51-62.

34 Corr S. Intensive, extensive, expensive: management of distal limb shearing injuries in cats. J Feline Med Surg 2009; 11: 747-757.

35 Kotz P, Fisher J, McCluskey P, et al. Use of a new silver barrier dressing, Alleyvin Ag in exuding chronic wounds. Int Wound J 2009; 6: 186-194.

36 Stinner DJ, Waterman SM, Masini BD, et al. Silver dressings augment the ability of negative pressure wound therapy to reduce bacteria in a contaminated open fracture model. I Trauma 2011; 71: S147-S150.

37 Percival SL, Thomas J, Linton S, et al. The antimicrobial efficacy of silver on antibiotic-resistant bacteria isolated from burn wounds. Int Wound J 2012; 9: 488-493.

38 Richards AJ, Hagelstein SM, Patel GK, et al. Early use of negative pressure therapy in combination with silver dressings in a difficult breast abscess. Int Wound J 2011; 8: 608-611.

39 Morykwas MJ, Faler BJ, Pearce DJ, et al. Effects of varying levels of subatmospheric pressure on the rate of granulation tissue formation in experimental wounds in swine. Ann Plast Surg 2001; 47: 547-551.

40 Saxena V, Hwang CW, Huang S, et al. Vacuum-assisted closure: microdeformations of wounds and cell proliferation. Plast Reconstr Surg 2004; 114: 1086-1096.

41 Lalliss SJ, Stinner DJ, Waterman SM, et al. Negative pressure wound therapy reduces pseudomonas wound contamination more than Staphylococcus aureus. J Orthop Trauma 2010; 24: 598-602.

42 Weed T, Ratliff C and Drake DB. Quantifying bacterial bioburden during negative pressure wound therapy: does the wound VAC enhance bacterial clearance? Ann Plast Surg 2004; 52: 276-279.

43 Moues CM, Vos MC, van den Bemd GJ, et al. Bacterial load in relation to vacuum-assisted closure wound therapy: a prospective randomized trial. Wound Repair Regen 2004; 12 : 11-17. 